Abstract THU0375 - Table 1

\begin{tabular}{lccc}
\hline & $\begin{array}{c}\text { Peripheral } \\
\text { center } \\
(\mathbf{n}=\mathbf{6 1})\end{array}$ & $\begin{array}{c}\text { Academic } \\
\text { center } \\
\mathbf{( n = 2 3 0 )}\end{array}$ & $\begin{array}{c}\mathbf{p}- \\
\text { value }\end{array}$ \\
\hline Age at diagnosis (years) & $33,6(9,23)$ & $31,3(9,01)$ & 0,08 \\
Male gender & $20(32,8)$ & $118(51,3)$ & $\mathbf{0 , 0 1}$ \\
HLA B27 positivity & $35(57,4)$ & $169(73,5)$ & $\mathbf{0 , 0 1}$ \\
Symptom duration at diagnosis (years) & $4,8(5,45)$ & $4,2(5,60)$ & 0,51 \\
ASAS classification criteria imaging & $46(75,4)$ & $204(88,7)$ & 0,21 \\
arm & & & \\
ASAS classification criteria clinical arm & $35(57,4)$ & $169(73,5)$ & $\mathbf{0 , 0 1}$ \\
ASAS classification criteria both arms & $23(37,7)$ & $145(63,0)$ & $\mathbf{0 , 0 1}$ \\
Arthritis & $11(18,0)$ & $39(17,0)$ & 0,99 \\
Dactylitis & $1(1,6)$ & $7(3,1)$ & 0,88 \\
Enthesitis & $11(18,0)$ & $28(12,2)$ & 0,33 \\
Psoriasis & $7(11,5)$ & $20(8,7)$ & 0,68 \\
Inflammatory bowel disease & $3(4,9)$ & $14(6,1)$ & 0,87 \\
Acute anterior uveitis & $6(9,8)$ & $32(13,9)$ & 0,53 \\
BMI (kg/m²) & $23,8(3,86)$ & $24,4(4,02)$ & 0,26 \\
BASMI & $1,1(1,13)$ & $1,3(1,17)$ & 0,33 \\
MASES + fascia plantaris (/15) & $1,4(2,50)$ & $0,9(1,54)$ & 0,69 \\
BASDAI (/100) & $46(19,3)$ & $43(20,2)$ & 0,31 \\
BASFI (/100) & $30(22,5)$ & $28(21,8)$ & 0,77 \\
ASDAS - CRP & $2,43(0,89)$ & $2,47(0,93)$ & 0,80 \\
\hline
\end{tabular}

Continuous variables: mean (SD); other: counts(\%).

Disclosure of Interests: Ann-Sophie De Craemer: None declared, Thomas Renson: None declared, Philippe Carron: None declared, Peggy Jacques: None declared, Jan Lenaerts: None declared, Lieve Gyselbrecht: None declared, Rik Joos: None declared, Filip van den Bosch Consultant for: AbbVie, BMS, Galapagos, Janssen, Lilly, Merck, Novartis, Pfizer and UCB, Speakers bureau: AbbVie, BMS, Janssen, Lilly, Merck, Novartis, Pfizer and UCB., Dirk Elewaut: None declared

DOI: 10.1136/annrheumdis-2019-eular.2467

\section{THU0376 THE VALUE OF SACROILIAC JOINT RADIOGRAPHS IN THE EARLY SPONDYLOARTHRITIS ESPERANZA COHORT}

Eugenio de Miguel ${ }^{1}$, Beatriz Joven-lbáñez ${ }^{2}$, Eva Galindez ${ }^{3}$, Claudia UrregoLaurín $^{4}$, Maria Luz García-Vivar ${ }^{3}$, Cristina Fernández-Carballido ${ }^{5}$, Jose Francisco Garcia Llorente ${ }^{6}$, María del Carmen Castro Villegas ${ }^{7}$, Carolina Tornero ${ }^{1}$, Xavier Juanola-Roura ${ }^{8}$, Esperanza Working Group. ' $\mathrm{La}$ Paz University Hospital, Rheumatology, Madrid, Spain; ${ }^{2} 12$ de Octubre University Hospital, Madrid, Spain; ${ }^{3}$ Basurto University Hospital, Rheumatology, Bilbao, Spain; ${ }^{4}$ Moncloa University Hospital, Madrid, Spain; ${ }^{5}$ San Juan University Hospital, Rheumatology, Alicante, Spain; ${ }^{6}$ Galdakao University Hospital, Rhematology, Billbao, Spain; ${ }^{7}$ Reina Sofía University Hospital, Rheumatology, Córdoba, Spain; ${ }^{8}$ Bellvitge University Hospital, Rheumatology, Barcelona, Spain

Background: X-Ray sacroilitis is the cornerstone in the diagnosis of the ankylosing spondylitis (AS). It is clear that the presence of sacroiliitis is a specific lesion in long standing AS, but little evidence exists on the reliability of this image technique in early axial spondyloarthritis $(\operatorname{axSpA})$, which associates with reduced structural damage. This is relevant because some rheumatologists and pharmacological authorities feel more confident with the diagnosis of AS rather than with non radiographic axial spondyloarthritis (nr-axSpA) forms. On the other hand, according to various research studies, clinicians are subject to potential bias when interpreting radiographs, influenced by their pretest clinical judgment.

Objectives: The aim of this study is to determine the value of X-Ray sacroilitis in the early diagnosis of axSpA.

Methods: This study included 290 radiographs of the $\mathrm{SI}$ joints from patients of the Esperanza early spondyloarthritis cohort. Nine readers, blinded for the diagnosis, participated in the reliability exercise, all of them experienced rheumatologists and members of the Spanish spondiloarthritis working group (GRESSER). Patients with axSpa were classified as having AS if the radiographic criteria of the modified NY criteria (presence of radiographic changes in the SIJ of at least grade II bilaterally or at least grade III unilaterally) were fulfilled. The gold standard was the categorical opinion of at least five of the expert readers. For the statistical analysis, the Chi-square and Kappa tests were performed.

Results: The radiographic diagnosis, sensitivity, specificity, likelihood ratio, grade of agreement and mean $\mathrm{K}$ values compared to gold standard are showed in table 1. The concordance Kappa test was highly variable among the readers, ranging from fair to excellent. The agreement with the gold standard varied from 68 to $94 \%$ and the sensitivity and specifity, from $50-100 \%$ and $64-96 \%$, respectively. Additionally, the number of AS was 61, with an inter-reader variability rate of 31 to 138 . Larger discrepancies were observed when assessing sacroilitis grade 2 .

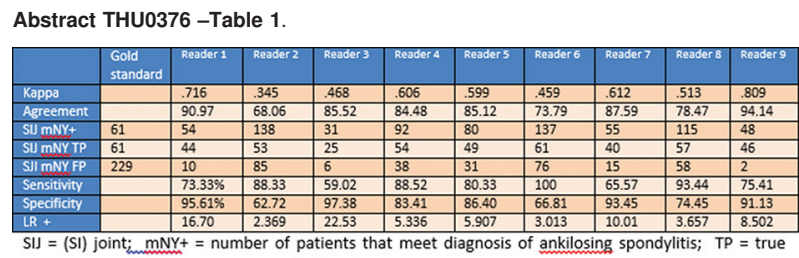

positives; $F P$ = false positives; $L R+=$ Likelihood ratio +

Conclusion: The diagnosis of AS in early axSpa is characterized by a marked variability. At least in doubtful cases, a second central evaluation performed by highly qualified experts should be advisable.

Disclosure of Interests: Eugenio de Miguel: None declared, Beatriz Joven-Ibáñez Speakers bureau: Celgene, Novartis, MSD, Pfizer, AbbVie, and Janssen, Eva Galindez: None declared, Claudia Urrego-Laurín: None declared, Maria Luz García-Vivar: None declared, Cristina Fernández-Carballido: None declared, Jose Francisco Garcia LLorente: None declared, María del Carmen Castro Villegas Paid instructor for: MSD, Abbvie, Pfizer, Janssen, Lilly, Roche, Carolina Tornero: None declared, Xavier Juanola-Roura: None declared

DOI: 10.1136/annrheumdis-2019-eular.7696

\section{THU0377 THE CARDIOVASCULAR ASSOCIATIONS WITH ENTHESITIS AND DACTYLITIS IN PATIENTS WITH SPONDYLOARTHRITIS: RESULTS FROM THE ASAS- COMOSPA STUDY}

Mohammad H. Derakhshan ${ }^{1}$, Nicola Goodson ${ }^{2}$, Jonathan Packham ${ }^{3}$, Raj Sengupta ${ }^{4}$, Anna Moltó ${ }^{5}$, Helena Marzo-Ortega ${ }^{6}$, Stefan Siebert ${ }^{\prime}$, On behalf of BRITSpA and the ASAS-COMOSPA investigators. ${ }^{1}$ University of Glasgow, Institute of Infection, Immunity and Inflammation, Glasgow, United Kingdom; ${ }^{2}$ University of Liverpool, Academic Rheumatology Department, Liverpool, United Kingdom; ${ }^{3}$ Keele University, Haywood Rheumatology Centre, Stoke on Trent, United Kingdom; ${ }^{4}$ Royal National Hospital for Rheumatic Diseases, Bath, United Kingdom; ${ }^{5}$ Hopital Cochin, Paris, France; ${ }^{6}$ University of Leeds, NIHR LBRC, Leeds, United Kingdom

Background: Enthesitis and dactylitis are considered characteristic inflammatory musculoskeletal manifestations of spondyloarthritis (SpA). These manifestations are usually assessed in the context of their assumed underlying specific condition rather than as distinct entities. Data from the ASAS-COMOSPA cohort have recently been shown that duration of SpA disease is associated with higher odds of hypertension particularly in axial $\mathrm{SpA}(1)$.

Objectives: To evaluate the possible associations of dactylitis and enthesitis phenotypes with cardiovascular comorbidities in a heterogeneous cohort of patients with SpA.

Methods: ASAS-COMOSPA is a global cross-sectional study assessing comorbidities in 3984 patients with SpA. History of enthesitis or dactylitis was based on self-report with confirmation using the medical records. Associations between dactylitis or enthesitis with hypertension, dyslipidaemia, diabetes, ischemic heart diseases (IHD) and stroke were analysed by separate logistic regression models unadjusted, adjusted for age and sex (models 1), and adjusted for age, sex and BMI (model 2).

Results: The data of 3905 participants were available for analysis. There were $1480(37.9 \%)$ with history of enthesitis and $611(15.6 \%)$ with dactylitis, while 1814 (46.5\%) had neither.

Presence of dactylitis was associated with hypertension in the univariable analysis [OR=1.68; $95 \% \mathrm{Cl}$ : $1.39-2.03]$. The association remained significant when adjusted for age and sex, but not following further adjustment for BMl (Table). Similarly, enthesitis was associated with hypertension in the univariable analysis [OR=1.36; $95 \% \mathrm{Cl}$ : 1.17-1.59], which remained after adjusted for age and sex, as well as after further adjustment for BMI (Table). Similar associations were seen for dyslipidaemia and dactylitis [OR=1.60; 95\%Cl: $1.29-1.98$ ] or enthesitis [OR=1.50; $95 \% \mathrm{Cl}: 1.26$ 1.77], with the association with dactylitis lost after further adjustment for BMI while the association with enthesitis remained significant (Table). While there were significant associations between dactylitis and diabetes [OR: $1.50(95 \% \mathrm{Cl}: 1.07-2.11)$ ], and between enthesitis and diabetes [OR=1.35; $95 \% \mathrm{Cl}: 1.02-1.78]$ in unadjusted models, no associations were 